Article

\title{
Gold Nanoclusters: Bridging Gold Complexes and Plasmonic Nanoparticles in Photophysical Properties
}

\author{
Meng Zhou ${ }^{\oplus}$, Chenjie Zeng, Qi Li, Tatsuya Higaki $₫$ and Rongchao Jin * \\ Department of Chemistry, Carnegie Mellon University, Pittsburgh, PA 15213, USA \\ * Correspondence: rongchao@andrew.cmu.edu
}

Received: 29 May 2019; Accepted: 25 June 2019; Published: 28 June 2019

check for updates

\begin{abstract}
Recent advances in the determination of crystal structures and studies of optical properties of gold nanoclusters in the size range from tens to hundreds of gold atoms have started to reveal the grand evolution from gold complexes to nanoclusters and further to plasmonic nanoparticles. However, a detailed comparison of their photophysical properties is still lacking. Here, we compared the excited state behaviors of gold complexes, nanolcusters, and plasmonic nanoparticles, as well as small organic molecules by choosing four typical examples including the $\mathrm{Au}_{10}$ complex, $\mathrm{Au}_{25}$ nanocluster (1 nm metal core), 13 diameter Au nanoparticles, and Rhodamine B. To compare their photophysical behaviors, we performed steady-state absorption, photoluminescence, and femtosecond transient absorption spectroscopic measurements. It was found that gold nanoclusters behave somewhat like small molecules, showing both rapid internal conversion $(<1 \mathrm{ps})$ and long-lived excited state lifetime (about $100 \mathrm{~ns}$ ). Unlike the nanocluster form in which metal-metal transitions dominate, gold complexes showed significant charge transfer between metal atoms and surface ligands. Plasmonic gold nanoparticles, on the other hand, had electrons being heated and cooled ( 100 ps time scale) after photo-excitation, and the relaxation was dominated by electron-electron scattering, electron-phonon coupling, and energy dissipation. In both nanoclusters and plasmonic nanoparticles, one can observe coherent oscillations of the metal core, but with different fundamental origins. Overall, this work provides some benchmarking features for organic dye molecules, organometallic complexes, metal nanoclusters, and plasmonic nanoparticles.
\end{abstract}

Keywords: gold nanomaterials; electron dynamics; phonon dynamics; optical properties

\section{Introduction}

Gold nanomaterials have attracted great interest in both fundamental science and practical applications such as sensing, catalysis, and optoelectronics owing to their unique properties [1-9]. For gold nanoparticles with diameters between 3-100 $\mathrm{nm}$, the strong surface plasmon resonance (SPR) dominates in the absorption spectrum, which is caused by collective excitation of free electrons. In contrast, ultra-small gold nanoparticles consisting of tens to hundreds of gold atoms, often called gold nanoclusters, show multiple absorption bands spanning the UV-visible NIR range because of discrete energy levels [10,11]. The significant progress in ligand-protected (e.g., thiolate) gold nanoclusters has allowed atomically precise control of their size and structure [11-13]. The structure of a thiolate-protected gold nanocluster typically consists of a metal core with Au-Au bonds $(\sim 2.8 \AA)$ and surface $\mathrm{Au}-\mathrm{S}$ staple motifs [11]. The $\mathrm{Au}(\mathrm{I})$ complexes, on the other hand, do not have a metal core, albeit gold aurophilic interactions ( $\mathrm{Au} \cdots \mathrm{Au}$ distance $>3 \AA$ ) often exist owing to the closed-shell $\mathrm{d}[10]$ configuration of $\mathrm{Au}(\mathrm{I})[14,15]$. Typically, solutions of gold complexes are colorless because their absorption peaks lie in the ultraviolet (UV) range (shorter than $400 \mathrm{~nm}$ ).

Plasmonic gold nanoparticles (AuNPs), gold nanoclusters, and $\mathrm{Au}(\mathrm{I})$ complexes have distinct optical features as a result of their differences in size, structure, and bonding. Therefore, understanding 
the photodynamics will help to deepen the understanding of their electronic structures and optical properties $[2,7,9,12,16-18]$. The electron dynamics of plasmonic gold nanoparticles has been intensively investigated $[19,20]$. Since the 1990s, El-Sayed and coworkers have probed the size and shape dependent electron dynamics of metallic AuNPs [21,22]. Hartland and Vallee groups have extensively investigated the phonon dynamics and electron-phonon coupling of different sized AuNPs [23,24]. In recent years, there has also been research on the excited state dynamics of ligand-protected gold nanoclusters [1,2,25-27]. The electron and phonon dynamics of the nanoclusters were found to be dependent on both size and structure [28-30]. Stamplecoskie and Kamat [31] found that the dynamics of $\mathrm{Au}(\mathrm{I})$ complexes are different from that of gold nanoclusters. Despite such progress, a systematic comparison of the photo-dynamics between them is still lacking.

Here, we chose Rhodamine $B(R B), A u_{10}(S R)_{10}$ complex, $A_{u_{25}}(S R)_{18}$ nanocluster, and $13 \mathrm{~nm}$ diameter AuNPs protected by citrate (Figure 1) as typical examples to compare the photophysics of small molecules, gold complexes, nanoclusters, and nanoparticles. We employed time-resolved fluorescence and femtosecond transient absorption spectroscopy to probe their excited state behaviors. The electron and phonon dynamics are discussed and compared in detail. The obtained results are of great importance to understand their optical response and further promote their applications in sensing and optics.

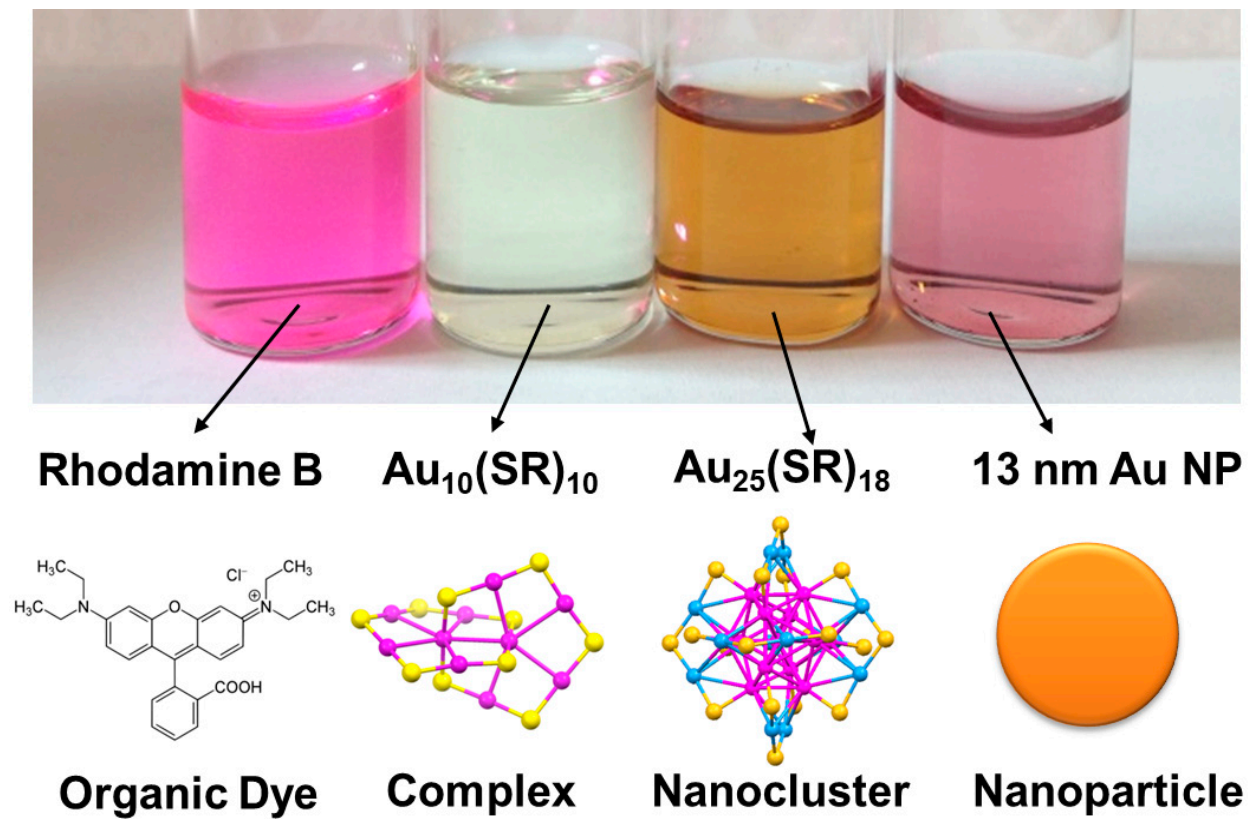

Figure 1. (Upper panel) Photograph of dilute solutions of Rhodamine $B$, sub-nanometer $\mathrm{Au}_{10}(\mathrm{SR})_{10}$

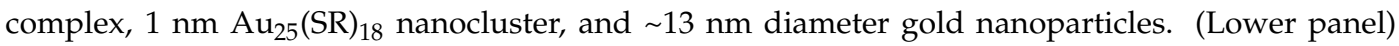
Molecular structures of Rhodamine $\mathrm{B}, \mathrm{Au}_{10}(\mathrm{SR})_{10}$ (where, $\mathrm{R}$ : $\mathrm{Ph}-{ }^{\mathrm{t}} \mathrm{Bu}$ ), and $\mathrm{Au}_{25}(\mathrm{SR})_{18}$ (where, R: $\mathrm{CH}_{2} \mathrm{CH}_{2} \mathrm{Ph}$ ). Color labels: yellow, $\mathrm{S}$ atoms; all other colors are for $\mathrm{Au}$. The $\mathrm{R}$ groups and citrate stabilizers on $\sim 13 \mathrm{~nm}$ Au nanoparticles are not shown.

\section{Materials and Methods}

Sample preparation: Rhodamine B was purchased from Sigma-Aldrich (St. Louis, MO, USA) and used as received. $\mathrm{Au}_{10}(\mathrm{SR})_{10}$ (where, $\mathrm{SR}=4$-tert-butylbenzenethiolate), $\mathrm{Au}_{25}(\mathrm{SR})_{18}$ (where, $\mathrm{SR}=2$-phenylethanethiol), and $13 \mathrm{~nm}$ diameter Au nanoparticles protected by trisodium citrate were prepared according to the literature [32,33]. 
Steady state absorption and photoluminescence: UV-vis absorption spectra were measured on a Shimadzu UV-3600plus spectrometer (Kyoto, Japan). Steady-state photoluminescence was measured on a Fluorolog-3 spectrofluorometer from Horiba Jobin Yvon (Piscataway, NJ, USA).

Time-resolved luminescence: fluorescence lifetimes were measured with a time-correlated single photon counting technique from Horiba Jobin Yvon (Piscataway, NJ, USA); a pulsed LED source (376 nm, $1.1 \mathrm{~ns}$ ) was used as the excitation source.

Transient absorption spectroscopy: Femtosecond transient absorption spectroscopy was carried out using a commercial Ti:Sapphire laser system (SpectraPhysics, $800 \mathrm{~nm}, 100 \mathrm{fs}, 3.5 \mathrm{~mJ}, 1 \mathrm{kHz}$ ) (Santa Clara, CA, USA). A pump pulse was generated using a commercial optical parametric amplifier (LightConversion, Vilnius, Lithuania). A small portion of the laser fundamental was focused into a sapphire plate to produce a supercontinuum in the visible region, which overlapped in time and space with the pump. Multi-wavelength transient spectra were recorded using dual spectrometers (i.e., signal and reference) (Thorlabs, Newton, NJ, USA) equipped with array detectors whose data rates exceed the repetition rate of the laser $(1 \mathrm{kHz})$. Solution samples in $1 \mathrm{~mm}$ path length cuvettes were excited by the tunable output of the OPA (pump). Nanosecond transient absorption measurements were conducted using the same ultrafast pump pulses along with an electronically delayed supercontinuum light source with a sub-nanosecond pulse duration (EOS, Ultrafast Systems, Sarasota, FL, USA).

\section{Results and Discussions}

Steady-state absorption and photoluminescence spectra: From the steady-state spectra, one can clearly observe the differences between small molecules and different-sized gold nanomaterials. The RB dye showed significant absorption peaks at $\sim 550 \mathrm{~nm}$ and a shoulder at $\sim 520 \mathrm{~nm}$ (Figure 2A), which originated from $0-0$ and $0-1$ vibronic peaks of $S_{1}$ state, respectively. Other absorption peaks at shorter wavelengths were transitions from the ground state to higher excited states than $S_{1}$. The fluorescence spectrum of RB exhibited a mirror image to the $S_{0}-S_{1}$ absorption band, with a Stokes shift of $0.1 \mathrm{eV}$. The $\mathrm{Au}_{10}$ complex, on the other hand, showed absorption in the UV region only, with a peak at $346 \mathrm{~nm}$ and a shoulder at $380 \mathrm{~nm}$ (Figure 2B). The higher energy transitions $(\lambda<300 \mathrm{~nm})$ originated from intraligand (IL) transitions, while the lower energy transitions (346 and 370 nm) should arise from ligand to metal or metal to ligand charge transfer (LM/MLCT) modified by $\mathrm{Au}(\mathrm{I})-\mathrm{Au}(\mathrm{I})$ interactions $[34,35]$. The $\mathrm{Au}_{10}$ complex showed no observable photoluminescence (PL); however, some of the other gold complexes were reported to exhibit strong PL [36-38]. Unlike gold complexes, the $\mathrm{Au}_{25}$ nanocluster exhibited multiple absorption bands spanning the entire UV-Vis range (Figure $2 \mathrm{C}$ ). Theoretical calculations revealed that the absorption band at $670 \mathrm{~nm}$ was from the $s p$ to $s p$ transition while absorption bands at shorter wavelengths involved both $s p$ to $s p$ and $d$ to $s p$ transitions [10]. The $\mathrm{Au}_{25}(\mathrm{SR})_{18}$ exhibited weak photoluminescence (QY < 1\%) related to the surface [39]. However, one can observe that the PL peak (centered at $750 \mathrm{~nm}$ ) overlapped with the lowest absorption band, which indicates that the emission in the visible region may not be the intrinsic PL of $\mathrm{Au}_{25}$ nanoclusters. As the size of particles further increased, more and more gold atoms contributed to the electronic states, and finally SPR emerged [8] in the UV-vis spectrum, such as the $\sim 13 \mathrm{~nm}$ Au nanoparticles (Figure 2D). Plasmonic gold nanoparticles had a continuous electronic band (i.e., the conduction band), and only had a very weak photoluminescence $\left(Q Y=10^{-4}\right)$ [40]. Below, we further discuss the excited state behaviors of these four species, from which one can find their molecular and plasmonic behaviors. 

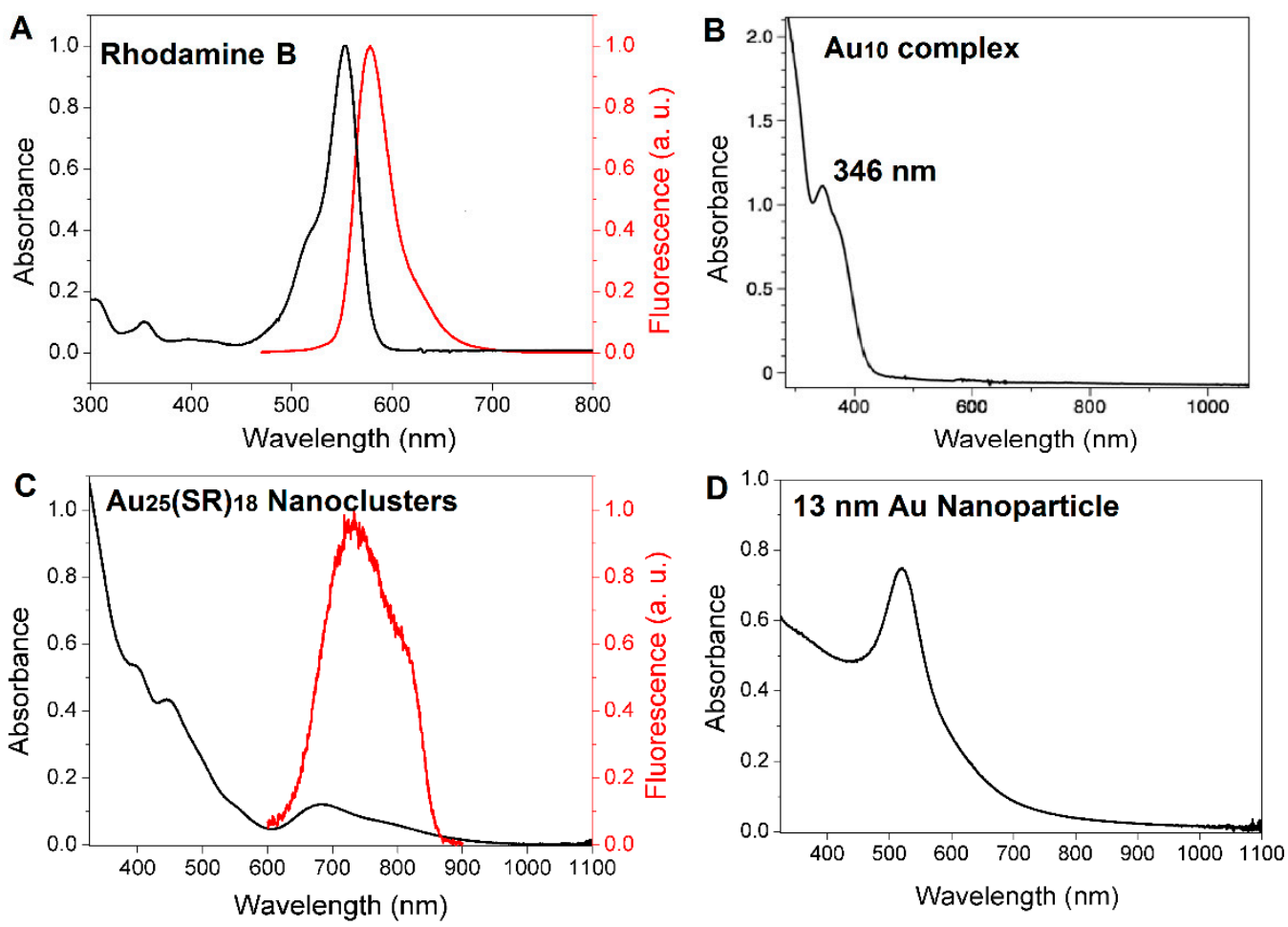

Figure 2. Steady-state optical spectra of (A) Rhodamine B; (B) complex $\mathrm{Au}_{10}(\mathrm{SR})_{10}$; (C) nanocluster $\mathrm{Au}_{25}(\mathrm{SR})_{18}$, and (D) $13 \mathrm{~nm}$ diameter Au nanoparticles.

Organic dyes (Rhodamine B): Before we discuss the photo-dynamics of different sized gold nanomaterials, we first discuss the excited state behavior of organic dyes such as Rhodamine B (RB) for an illustration of molecular behavior. The RB has been widely used as a probe in biological and synthetic polyelectrolyte systems [41]. The excited state behavior of organic dyes has been intensively investigated ever since the birth of time-resolved spectroscopy [42-44]. An aqueous solution of RB has strong luminescence $(\mathrm{QY}=30 \%$ ) and the PL lifetime is determined to be $1.7 \mathrm{~ns}$ in water (see Figure $\mathrm{S} 1$ in the Supplementary Materials). It is worth noting that the excited state lifetime of RB is highly dependent on solvent polarity (Figure S1), which has been reported previously [45]. In our current work, the transient absorption spectroscopic measurement on RB was performed with excitations at $360 \mathrm{~nm}$ and $560 \mathrm{~nm}$, respectively, to excite the sample to the second and first singlet excited state. Upon photo-excitation, one can observe excited state absorption (ESA) around $450 \mathrm{~nm}$, ground state bleaching (GSB), and stimulated emission (SE) between $500 \mathrm{~nm}$ and $700 \mathrm{~nm}$ (Figure 3A,B). With $360 \mathrm{~nm}$ excitation, one can observe an ultrafast decay ( 100 fs) in GSB at $520 \mathrm{~nm}$ (Figure 3C, blue dip) as well as a rise in SE at $630 \mathrm{~nm}$ (Figure 3C, black). On the other hand, the ultrafast decay component was absent with excitation at $560 \mathrm{~nm}$ (Figure 3D); thus, the $100 \mathrm{fs}$ component was assigned as internal conversion from $S_{2}$ to $S_{1}$ state. From the kinetic traces, ESA, GSB, and SE decay simultaneously from 1 ps to $3 \mathrm{~ns}$ and the transient absorption (TA) lifetime (1.7 ns) matched well with the PL lifetime (Table S1 in SI). The TA spectra and decay dynamics of RB we observed here matched well with the results of previous studies [44,45]. 

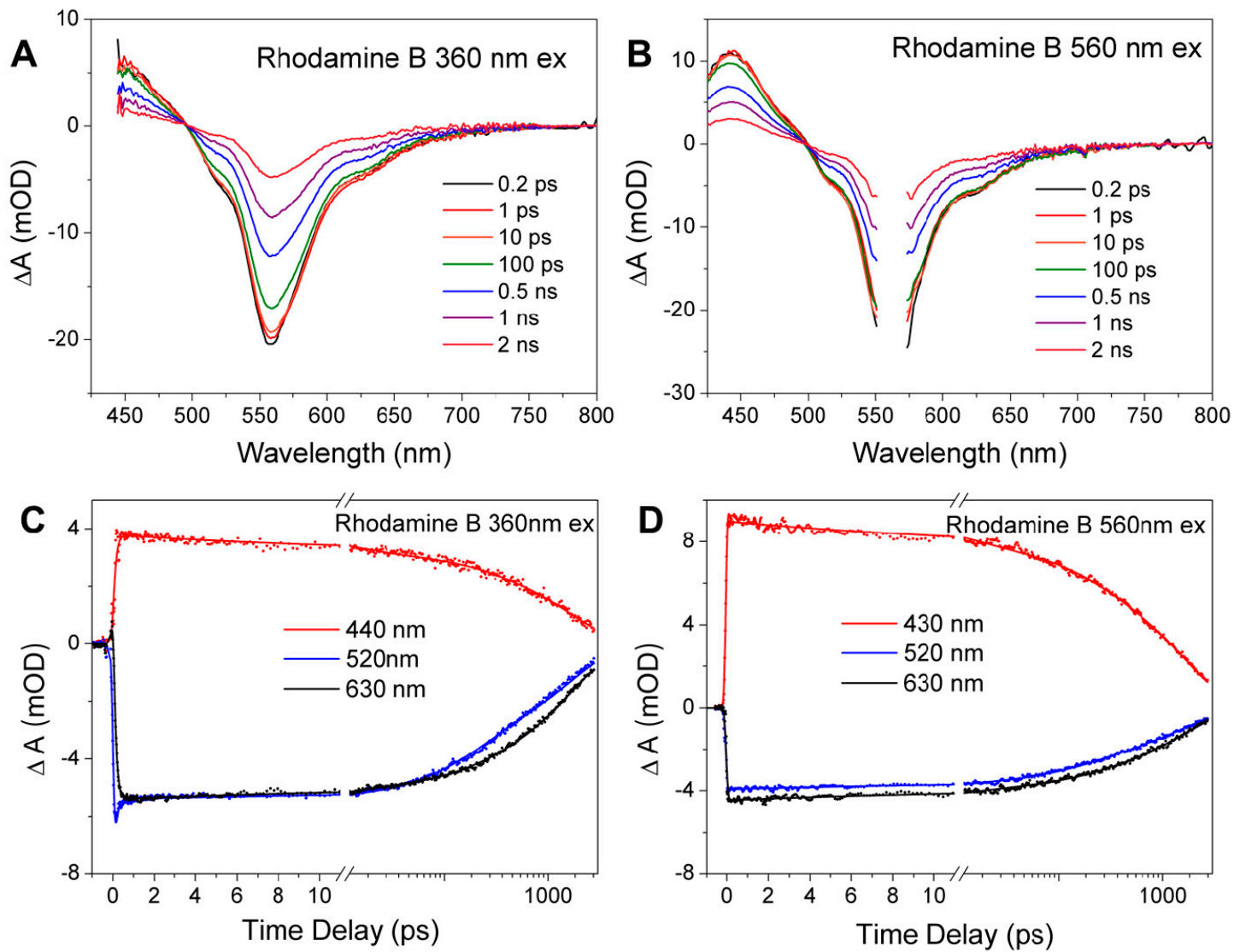

Figure 3. (A,B) Transient absorption spectra of Rhodamine B (dissolved in water) at different time delays with excitation of $360 \mathrm{~nm}$ and $560 \mathrm{~nm}$, respectively. (C,D) Transient absorption decays at different probe wavelengths.

To sum up, the photophysics of RB and other typical organic dye molecules can be well explained by the Jablonski diagram and the relaxation follows the Kasha's rule [46], that is, the excited state molecules first experience a rapid non-radiative relaxation to the lowest singlet excited state and then emit photons to relax to the ground state.

Gold complexes $\left(\mathrm{Au}_{10}(\mathrm{SR})_{10}\right)$ : Gold complexes are composed of one or a few gold atoms coordinated by ligands. The $\mathrm{Au}_{10}(\mathrm{SR})_{10}$ complex is composed of two interlocked $\mathrm{Au}_{5}(\mathrm{SR})_{5}$ rings and every gold atom is connected to two $S$ atoms [32]. Upon photoexcitation at $\lambda=365 \mathrm{~nm}$, broad positive signals were observed (Figure 4A) with no GSB signal, so the transient signal originates solely from ESA. Such an observation has also been reported in other Au(I) complexes [47]. In the initial $36 \mathrm{ps,}$ the ESA1 around $780 \mathrm{~nm}$ decays to give rise to the ESA2 at $535 \mathrm{~nm}$ (Figure 4B). In the following $2.8 \mathrm{~ns}$, ESA at all wavelengths decay dramatically by $90 \%$. Decay associated spectra (DAS) obtained by global analysis and singular value decomposition (SVD) of the TA data exhibited three decaying components, 14 ps, 290 ps, and $>1$ ns (Figure 4C,D). Considering that gold-thiolate complexes show LM/MLCT characteristics in their steady-state UV-vis spectra, photo-excitation at $365 \mathrm{~nm}$ can directly generate LM/MLCT excited state $[35,37,47]$. The first 14 ps process can be assigned to the stabilization and equilibrium of LM/MLCT state. In a previous study, we probed the photodynamics of $\mathrm{Au}_{10}$ complexes dissolved in toluene and dichloromethane and found that the decay lifetime was dependent on solvent polarity [48]. Here, we repeated the TA spectra of $\mathrm{Au}_{10}$ dissolved in dichloromethane and the same processes can be observed with similar time constants to those in the previous study. Upon photoexcitation, intersystem crossing (ISC) from ${ }^{1} \mathrm{LM} / \mathrm{MLCT}$ to ${ }^{3} \mathrm{LM} / \mathrm{MLCT}$ occurred in less than $100 \mathrm{fs}$, which was not resolved in our TA measurement. The ${ }^{3} \mathrm{LM} / \mathrm{MLCT}$ state was then stabilized in tens of picoseconds to form a ${ }^{3} \mathrm{LM} / \mathrm{MLCT}^{*}$ state, which decayed to the ground state (Figure 5). 

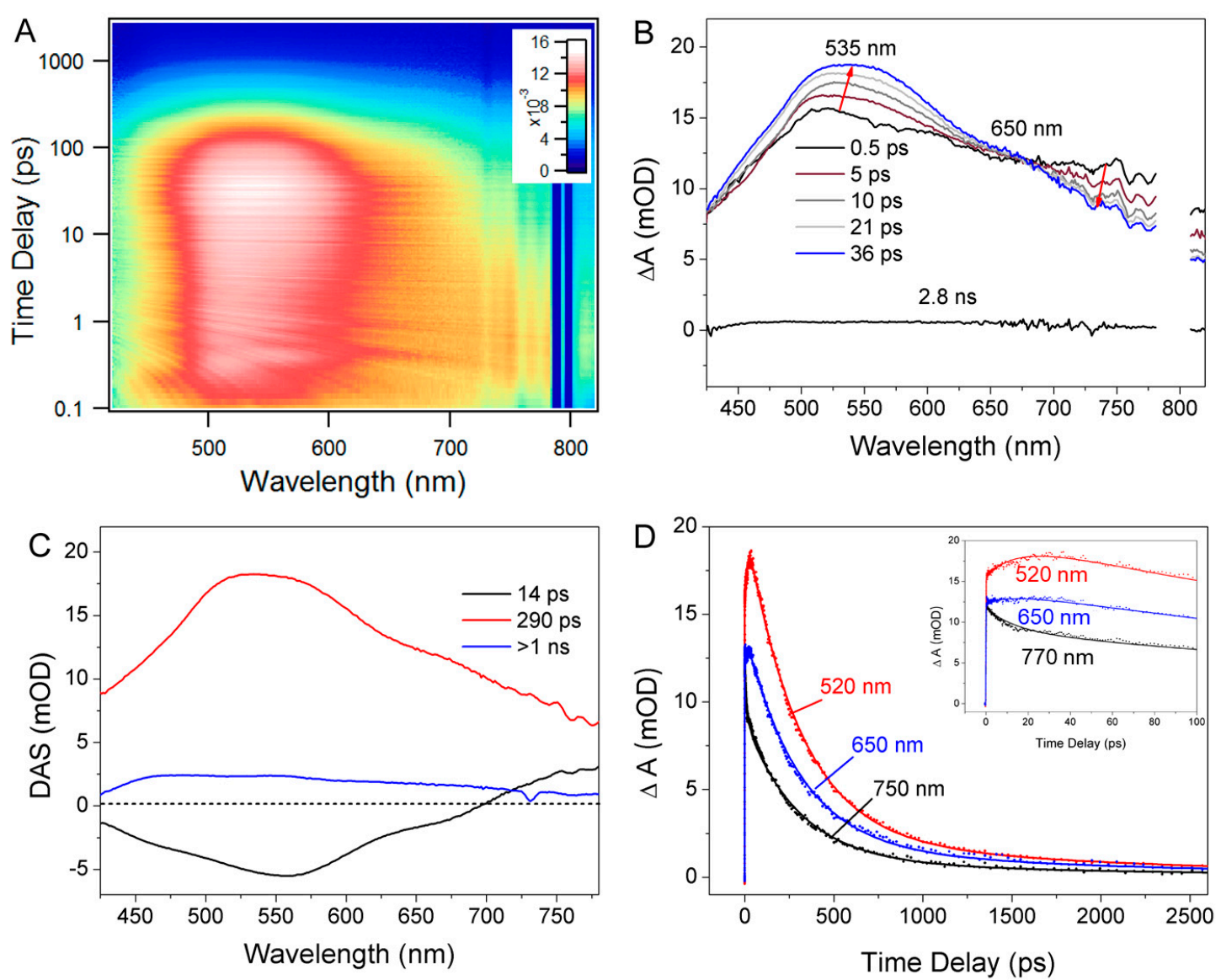

Figure 4. (A) Transient absorption (fs-TA) data of $\mathrm{Au}_{10}$ complex dissolved in dichloromethane. (B) Transient absorption spectra as a function of time delay from 0.5 ps to 36 ps and that at $2.8 \mathrm{~ns}$. Scattering due to the laser pulse was excluded around $800 \mathrm{~nm}$ for $(\mathbf{A}, \mathbf{B})$. (C) Decay associated spectra (DAS) obtained from the global analysis of the TA data. (D) Kinetic traces (dots) and corresponding fit (solid line) at selected wavelengths, which shows the quality of the fitting.

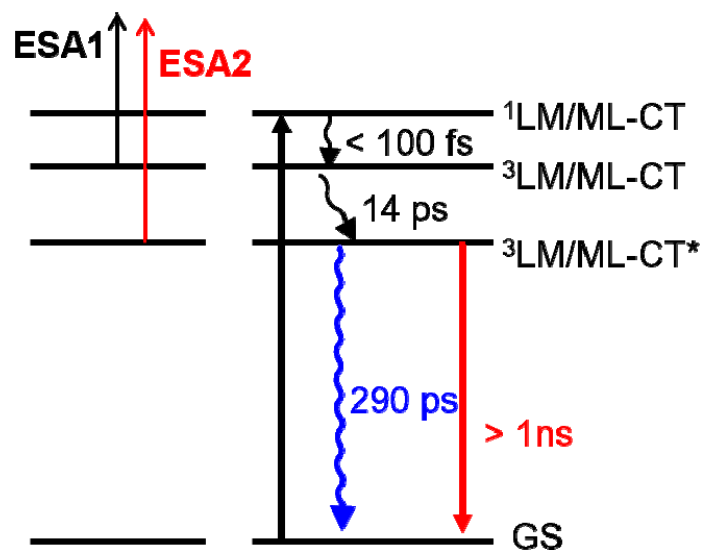

Figure 5. Diagram for the relaxation dynamics in the $\mathrm{Au}_{10}$ complex. The $290 \mathrm{ps}$ process shows solvent dependency (dichloromethane in this study versus $350 \mathrm{ps}$ in toluene in a previous study [48]).

Nanoclusters ( $\mathrm{Au}_{25}(\mathrm{SR})_{18}$ as the example): Unlike homoleptic gold complexes, thiolate-protected gold nanoclusters are composed of a well-defined metal core and surface staple motifs (e.g., -S-Au-S-) [11]. The relaxation dynamics of gold nanoclusters of different structures have been investigated by several groups and the relaxation model is more complicated as a result of multiple contributions of both $\mathrm{Au}$ and $\mathrm{S}$ atoms to the orbitals $[27,28,49,50]$. Here, $\mathrm{Au}_{25}(\mathrm{SR})_{18}$ was chosen as an 
example to illustrate the photophysics. The $\mathrm{Au}_{25}(\mathrm{SR})_{18}$ structure consisted of an icosahedral $\mathrm{Au}_{13}$ core and six $\mathrm{Au}_{2}(\mathrm{SR})_{3}$ dimeric staple motifs for surface protection (Figure 1) [10]. With excitation at $490 \mathrm{~nm}$, one can observe broad ESA overlapped with GSB peaks at $510 \mathrm{~nm}, 550 \mathrm{~nm}$, and $675 \mathrm{~nm}$ (Figure 6A), which is a typical feature of gold nanoclusters [2,50,51]. During the first picosecond, one can observe a broad ESA band between $500 \mathrm{~nm}$ and $620 \mathrm{~nm}$ decaying rapidly and the time constant was $600 \mathrm{fs}$ (Figure 6B). The rapid relaxation was not observed under excitation of $800 \mathrm{~nm}$ (Figure 6C), which suggests that it should be internal conversion from higher to lower excited states. With excitation at $800 \mathrm{~nm}$, the TA spectrum at $\sim 0.3$ ps was equal to the spectrum with excitation at $490 \mathrm{~nm}$ after 2 ps, which indicates that the $800 \mathrm{~nm}$ pulse excited $\mathrm{Au}_{25}$ directly to the lower excited state. The TA signal did not decay significantly between 2 ps and 3 ns, indicating a significantly longer excited state lifetime of $\mathrm{Au}_{25}$ than $3 \mathrm{~ns}$. It was also interesting to see that the nanosecond TA and time resolved-PL give different lifetimes (Figure S2 in the Supplementary Materials). Compared with the dynamics of the $\mathrm{Au}_{10}$ complex, the excited state dynamics of the $\mathrm{Au}_{25}$ nanoclusters behaved more like that of small molecules.
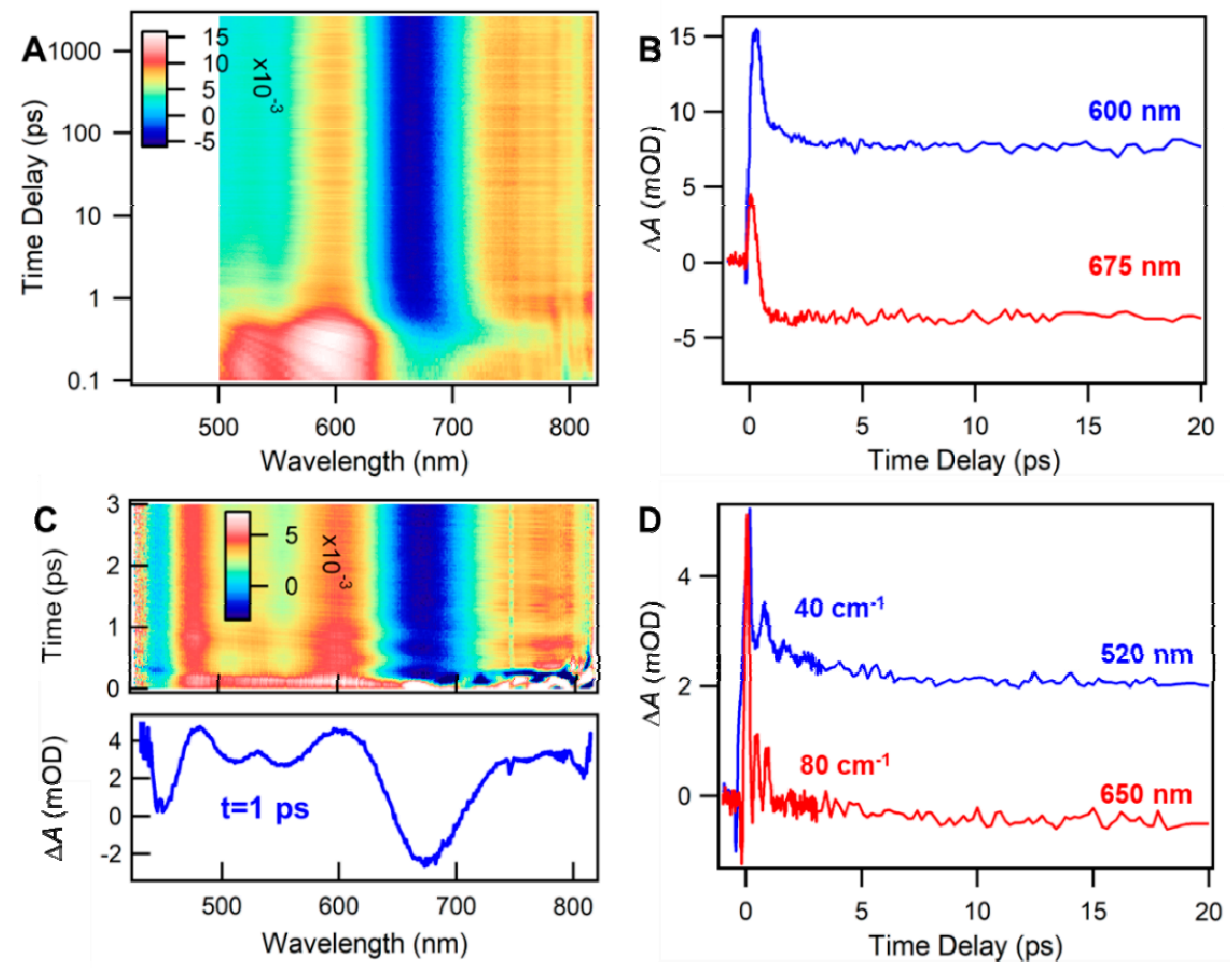

Figure 6. (A) Transient absorption data map of $\mathrm{Au}_{25}(\mathrm{SR})_{18}$ with excitation at $490 \mathrm{~nm}$; (B) kinetic traces probed at selected wavelengths with excitation at $490 \mathrm{~nm}$. (C) Transient absorption data map and spectra probed at $1 \mathrm{ps}$ with $800 \mathrm{~nm}$ excitation; (D) kinetic traces probe at $520 \mathrm{~nm} 650 \mathrm{~nm}$ with excitation at $800 \mathrm{~nm}$.

With excitation at $800 \mathrm{~nm}$, one can also observe coherent oscillations in the first few picoseconds (Figure 6C,D). Two frequencies $\left(40 \mathrm{~cm}^{-1}\right.$ and $\left.80 \mathrm{~cm}^{-1}\right)$ were exhibited at different probe wavelengths (Figure 6D), which have been reported previously [51]. These oscillations observed in TA decays, also observed in other nanoclusters [52,53], were assigned to acoustic vibrations of the metal core and explained as displacive excitation [52,54], similar to that observed in semiconductors and small molecules [54,55].

Plasmonic nanoparticles (13 nm diameter AuNPs): As the particle size becomes larger, more gold atoms will contribute to the electronic states, and eventually the bandgap will disappear, giving rise to a transition from non-metallic to metallic [8]. The TA spectra of $13 \mathrm{~nm}$ AuNPs showed a significant bleaching signal at $520 \mathrm{~nm}$ and ESA on two sides (Figure 7A). We found that (i) the GSB became sharper 
from 0.2 ps to 5 ps and (ii) the higher pump fluence gave rise to a broader bleaching signal compared to that of the lower pump fluence (Figure 7A,B). The broadening of GSB in the initial time delay (full width at half maximum decreased from $50 \mathrm{~nm}$ to $30 \mathrm{~nm}$ in Figure 7A) is ascribed to the heating effect [20]. Upon photo-excitation, electrons in the AuNPs will be heated to a very high temperature (e.g., $1000 \mathrm{~K}$, depending on the pump power). Heating the nanoparticle will result in broadening of the SPR peak as well as the GSB in the TA spectra. After the electrons are heated to a very high temperature, the excited state energy will first reach equilibrium via electron-electron scattering (manifested in the $100 \mathrm{fs}$ rise of the kinetic traces in Figure 7C). Subsequently, the energy will be transferred from the electrons to the lattice through electron-phonon coupling (1-5 ps rapid decay in Figure 7C) [3,24]. Accompanied by the rapid decay, the GSB will also be narrowed during the electron-phonon coupling process (Figure 7A,B). Finally, the energy will dissipate into the environment by phonon-phonon relaxation, which is dependent on the surrounding medium (100 ps decay in Figure 7C). As there is no bandgap in plasmonic Au nanoparticles, there is no electron-hole separation or recombination process as in nanoclusters. Instead, the relaxation dynamics can be described by a well-established two-temperature model $[21,56]$. With the high pump fluence, one can observe a prominent oscillation with a frequency of $7.5 \mathrm{~cm}^{-1}$ (4 ps in periods) in the $13 \mathrm{~nm}$ AuNPs (Figure 7D). Unlike that of the gold nanoclusters, the oscillations in the metallic AuNPs originated from the periodic shift of the SPR band due to the lattice expansion induced by laser heating [20]. In addition, the oscillations in the metallic NPs can be well modelled by a classical continuum model (scaling as $1 / D$, where $D$ is the diameter), but this model fails in gold nanoclusters.
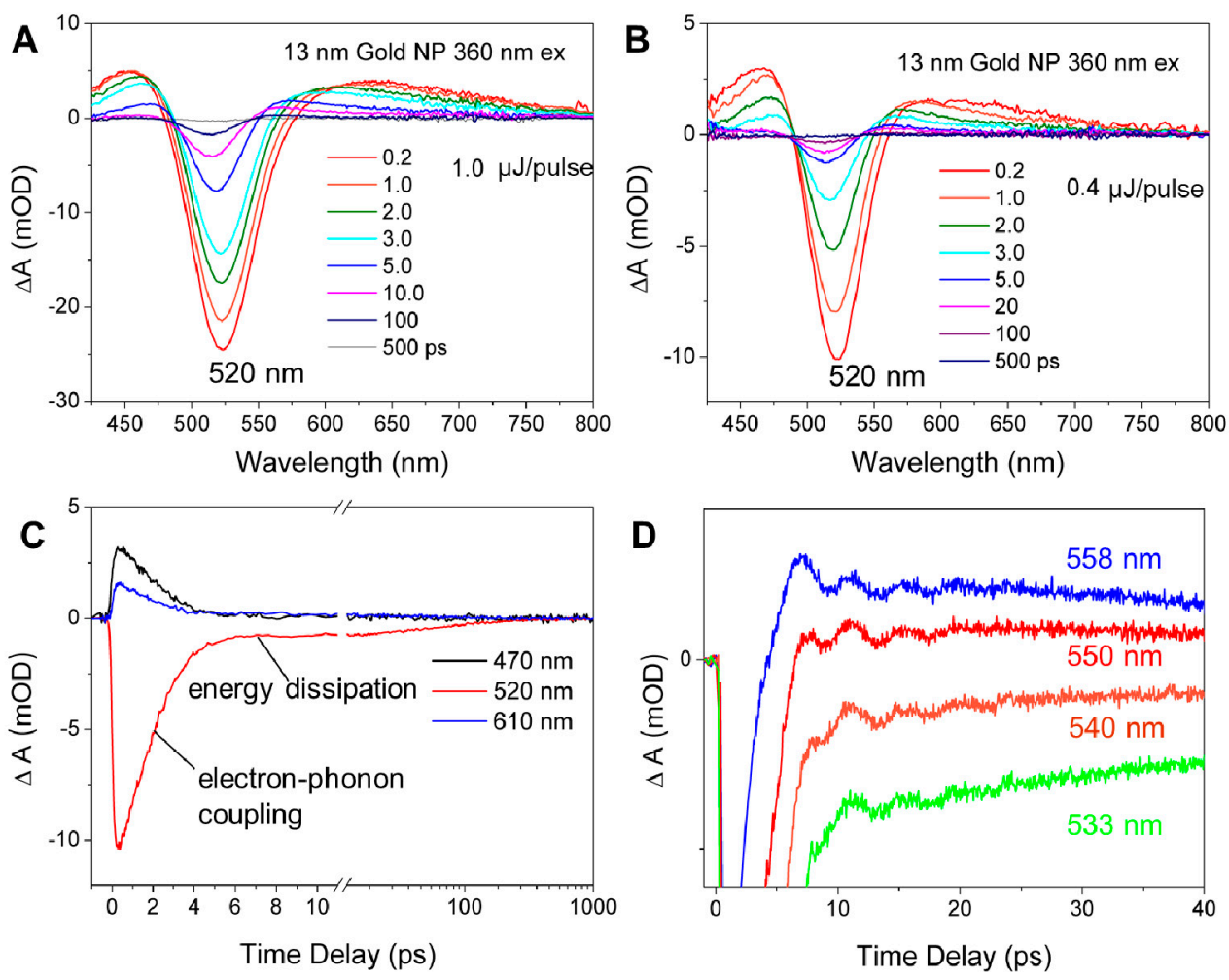

Figure 7. (A,B) Transient absorption spectra of $13 \mathrm{~nm}$ AuNPs at different time delays with an excitation of $360 \mathrm{~nm}$ under high and low pump fluences; (C) TA decay traces at selected probe wavelengths; (D) kinetic traces with prominent oscillation features. 
A distinct feature of metallic gold nanoparticles is that the electron-phonon coupling is dependent on pump fluence $[3,19]$. When the pump fluence increased from 80 to $1800 \mathrm{uJ} / \mathrm{cm}^{2}$, one can clearly observe that the electron-phonon coupling slowed down significantly (Figure 8A). After plotting the fitted time constants as a function of laser fluence, a linear relationship can be observed (Figure 8B), which agrees well with previous studies $[3,56]$. Such a power dependence is only observed in plasmonic nanoparticles, which can be well explained by the two-temperature model [21]. Compared to the plasmonic NPs, the TA measurements of $\mathrm{RB}, \mathrm{Au}_{10}$ complex, and $\mathrm{Au}_{25}$ nanoclusters under different pump fluences exhibited no differences in the decay dynamics (Figures S3-S5 in the Supplementary Materials), hence, they were power independent. This serves as a signature of the non-metallic state. In Table 1, the photophysical features of the four types of materials are summarized. In Scheme 1, the relaxation processes as well as the time constants are illustrated.
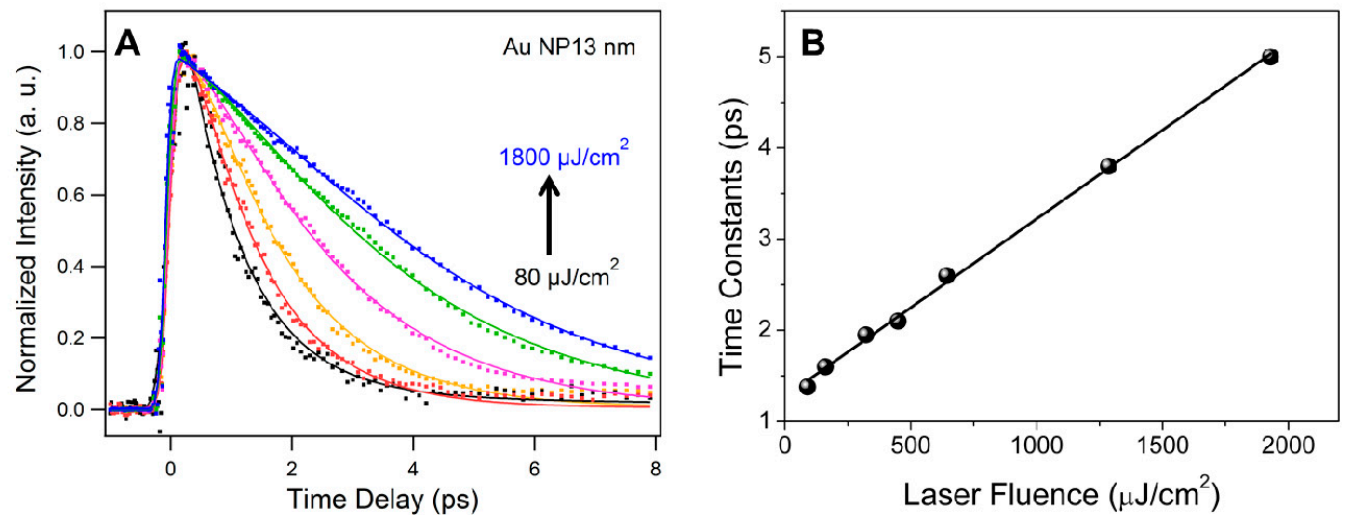

Figure 8. (A) Kinetic traces probe at $520 \mathrm{~nm}$ with different pump fluences; (B) electron-phonon time constants as a function of pump fluence.

Table 1. Characteristic features of molecules, complexes, nanoclusters, and plasmonic nanoparticles (PL: photoluminescence; ESA: excited state absorption; GSB: ground-state bleach; SE: stimulated emission; IC: internal conversion; ISC: intersystem crossing).

\begin{tabular}{|c|c|c|c|c|c|}
\hline & Structure & $E_{\mathrm{g}}$ & $\begin{array}{c}\text { Steady-State } \\
\text { abs. }\end{array}$ & PL & Transient Absorption \\
\hline $\begin{array}{c}\text { Dye molecules } \\
\text { e.g.' } \\
\text { Rhodamine B }\end{array}$ & No core & $>1-2 \mathrm{eV}$ & $\begin{array}{l}\text { Multiple bands } \\
\text { (e.g., } \pi-\pi \\
\text { transition) }\end{array}$ & Yes & $\begin{array}{c}\mathrm{ESA}+\mathrm{GSB}+\mathrm{SE}, \\
\mathrm{IC}, \mathrm{ISC}, \text { long lifetime } \\
\text { (ns), } \\
\text { power independence }\end{array}$ \\
\hline $\begin{array}{c}\text { Complexes, } \\
\text { e.g., } \mathrm{Au}_{10}(\mathrm{SR})_{10}\end{array}$ & No core & $>2 \mathrm{eV}$ & $\begin{array}{l}\text { Multiple bands } \\
\text { (charge transfer, } \\
\text { CT) }\end{array}$ & Yes & $\begin{array}{c}\text { ESA (predominant), } \\
\text { ISC, long lifetime } \\
(\mu s-n s), \\
\text { power independence }\end{array}$ \\
\hline $\begin{array}{l}\text { Nanoclusters, } \\
\text { e.g., } \mathrm{Au}_{25}(\mathrm{SR})_{18}\end{array}$ & $\begin{array}{l}\text { Core + surface } \\
\text { (staple motifs) }\end{array}$ & $\sim 2.5 \mathrm{eV}$ to zero & $\begin{array}{l}\text { Multiple bands } \\
\text { (metal } \\
\text { core-based }+ \\
\text { metal } \leftrightarrow \text { ligand } \\
\text { CT) }\end{array}$ & Yes & $\begin{array}{c}\text { ESA + GSB, acoustic } \\
\text { vibrations, } \\
\text { IC, ISC, varying } \\
\text { lifetime (ns-ps), } \\
\text { power independence }\end{array}$ \\
\hline $\begin{array}{c}\text { Plasmonic NPs, } \\
\text { e.g., } 13 \mathrm{~nm} \\
\text { AuNPs }\end{array}$ & Core + surface & Zero & $\begin{array}{c}\text { Single-band } \\
\text { SPR } \\
\text { (nanospheres) }\end{array}$ & Negligible & $\begin{array}{c}\text { GSB, acoustic } \\
\text { vibrations, } \\
\text { short lifetime (ps), } \\
\text { power dependence }\end{array}$ \\
\hline
\end{tabular}




$$
\begin{aligned}
& \text { RhB: } \mathrm{S}_{\mathrm{n}} \stackrel{<100 \mathrm{fs}}{\longrightarrow} \mathrm{S}_{1} \stackrel{1.7 \mathrm{~ns}}{\longrightarrow} \mathrm{G} \\
& \mathbf{A u}_{10}:{ }^{1} \mathrm{LM} / \mathrm{MLCT} \stackrel{<100 \mathrm{fs}}{\longrightarrow}{ }^{3} \mathrm{LM} / \mathrm{MLCT} \stackrel{14 \mathrm{ps}}{\longrightarrow}{ }^{3} \mathrm{LM} / \mathrm{MLCT}^{*} \stackrel{>1 \mathrm{~ns}}{\longrightarrow} \mathrm{G} \\
& \mathbf{A u}_{25} \text { : higher excited state } \stackrel{<1 \mathrm{ps}}{\longrightarrow} \text { lower excited state } \stackrel{\sim 100 \mathrm{~ns}}{\longrightarrow} \mathrm{G} \\
& \text { Au NP: e-e scattering } \longrightarrow \text { e-ph coupling } \longrightarrow \text { energy dissipation }
\end{aligned}
$$

Scheme 1. Relaxation pathways and time constants of four types of materials. G stands for ground state, e-e scattering stands for electron-electron scattering, e-ph coupling stands for electron-phonon coupling.

\section{Conclusions}

In summary, we have compared the photophysical properties of small organic molecules, gold complexes (no explicit core), nanoclusters (with a core and surface Au-S staples), and metallic-state nanoparticles by choosing four examples (Rhodamine $\mathrm{B}, \mathrm{Au}_{10}(\mathrm{SR})_{10}, \mathrm{Au}_{25}(\mathrm{SR})_{18}$, and $13 \mathrm{~nm}$ diameter AuNPs). Femtosecond transient absorption spectroscopy was used to determine their relaxation time constants and photodynamics. Overall, gold nanoclusters behave similarly to small molecules, for example, showing a rapid internal conversion $(<1 \mathrm{ps})$ and a long-lived excited state lifetime ( $100 \mathrm{~ns})$. In $\mathrm{Au}(\mathrm{I})$ complexes, LM/MLCT charge transfer states dominate the relaxation dynamics and no sub-picosecond relaxation was observed. On the other hand, the electron dynamics of plasmonic gold nanoparticles can be well explained by a two-temperature model, with no electron-hole separation or recombination being observed. Overall, the revealed features in photodynamics of the four different materials provide some benchmarking features and are expected to be of great importance for understanding their electronic structures and broadening their applications in various fields in future work.

Supplementary Materials: The Supplementary Materials are available online at http://www.mdpi.com/2079-4991/ 9/7/933/s1.

Author Contributions: R.J. designed the study; M.Z., C.Z., Q.L. and T.H. performed the experiments and analyzed the data. All authors discussed the results and commented on the manuscript.

Funding: This research was funded by the National Science Foundation (DMR-1808675).

Conflicts of Interest: The authors declare no conflict of interest.

\section{References}

1. Yau, S.H.; Varnavski, O.; Goodson, T. An ultrafast look at Au nanoclusters. Acc. Chem. Res. 2013, 46, 1506-1516. [CrossRef] [PubMed]

2. Zhou, M.; Higaki, T.; Hu, G.; Sfeir, M.Y.; Chen, Y.; Jiang, D.; Jin, R. Three-orders-of-magnitude variation of carrier lifetimes with crystal phase of gold nanoclusters. Science 2019, 364, 279-282. [PubMed]

3. Hartland, G.V. Optical studies of dynamics in noble metal nanostructures. Chem. Rev. 2011, 111, 3858-3887. [CrossRef] [PubMed]

4. Zhou, M.; Zeng, C.; Song, Y.; Padelford, J.W.; Wang, G.; Sfeir, M.Y.; Higaki, T.; Jin, R. On the non-metallicity of $2.2 \mathrm{~nm} \mathrm{Au} 246$ (SR) 80 nanoclusters. Angew. Chem. Int. Ed. 2017, 129, 16475-16479. [CrossRef]

5. Bain, D.; Paramanik, B.; Patra, A. Silver(I)-induced conformation change of DNA: Gold nanocluster as a spectroscopic probe. J. Phys. Chem. C 2017, 121, 4608-4617. [CrossRef]

6. Paramanik, B.; Bain, D.; Patra, A. Making and breaking of DNA-metal base pairs: $\mathrm{Hg}^{2+}$ and Au nanocluster based off/on probe. J. Phys. Chem. C 2016, 120, 17127-17135. [CrossRef] 
7. Guan, Z.; Gao, N.; Jiang, X.-F.; Yuan, P.; Han, F.; Xu, Q.-H. Huge enhancement in two-photon photoluminescence of au nanoparticle clusters revealed by single-particle spectroscopy. J. Am. Chem. Soc. 2013, 135, 7272-7277. [CrossRef]

8. Higaki, T.; Zhou, M.; Lambright, K.J.; Kirschbaum, K.; Sfeir, M.Y.; Jin, R. Sharp transition from nonmetallic $\mathrm{Au}_{246}$ to metallic $\mathrm{Au}_{279}$ with nascent surface plasmon resonance. J. Am. Chem. Soc. 2018, 140, 5691-5695. [CrossRef]

9. Russier-Antoine, I.; Bertorelle, F.; Vojkovic, M.; Rayane, D.; Salmon, E.; Jonin, C.; Dugourd, P.; Antoine, R.; Brevet, P.-F. Non-linear optical properties of gold quantum clusters. The smaller the better. Nanoscale 2014, 6 , 13572-13578. [CrossRef]

10. Zhu, M.; Aikens, C.M.; Hollander, F.J.; Schatz, G.C.; Jin, R. Correlating the crystal structure of a thiol-protected $\mathrm{Au}_{25}$ cluster and optical properties. J. Am. Chem. Soc. 2008, 130, 5883-5885. [CrossRef]

11. Jin, R.; Zeng, C.; Zhou, M.; Chen, Y. Atomically precise colloidal metal nanoclusters and nanoparticles: Fundamentals and opportunities. Chem. Rev. 2016, 116, 10346-10413. [CrossRef] [PubMed]

12. Olesiak-Banska, J.; Waszkielewicz, M.; Samoc, M. Two-photon chiro-optical properties of gold Au 25 nanoclusters. Phys. Chem. Chem. Phys. 2018, 20, 24523-24526. [CrossRef] [PubMed]

13. Zeng, C.; Chen, Y.; Kirschbaum, K.; Lambright, K.J.; Jin, R. Emergence of hierarchical structural complexities in nanoparticles and their assembly. Science 2016, 354, 1580-1584. [CrossRef] [PubMed]

14. Che, C.-M.; Lai, S.-W. Luminescence and photophysics of gold complexes. In Gold Chemistry; Wiley-VCH/Verlag GmbH \& Co. KGaA: Weinheim, Germany, 2009; pp. 249-281.

15. Yam, V.W.-W.; Au, V.K.-M.; Leung, S.Y.-L. Light-emitting self-assembled materials based on $\mathrm{d}^{8}$ and $\mathrm{d}^{10}$ transition metal complexes. Chem. Rev. 2015, 115, 7589-7728. [CrossRef] [PubMed]

16. Yu, K.; You, G.; Polavarapu, L.; Xu, Q.-H. Bimetallic Au/Ag core-shell nanorods studied by ultrafast transient absorption spectroscopy under selective excitation. J. Phys. Chem. C 2011, 115, 14000-14005. [CrossRef]

17. Olesiak-Banska, J.; Gordel, M.; Matczyszyn, K.; Shynkar, V.; Zyss, J.; Samoc, M. Gold nanorods as multifunctional probes in a liquid crystalline DNA matrix. Nanoscale 2013, 5, 10975-10981. [CrossRef] [PubMed]

18. Minutella, E.; Schulz, F.; Lange, H. Excitation-dependence of plasmon-induced hot electrons in gold nanoparticles. J. Phys. Chem. Lett. 2017, 4925-4929. [CrossRef]

19. Link, S.; El-Sayed, M.A. Optical properties and ultrafast dynamics of metallic nanocrystals. Annu. Rev. Phys. Chem. 2003, 54, 331-366. [CrossRef]

20. Hartland, G.V. Coherent excitation of vibrational modes in metallic nanoparticles. Annu. Rev. Phys. Chem. 2006, 57, 403-430. [CrossRef]

21. Link, S.; Beeby, A.; FitzGerald, S.; El-Sayed, M.A.; Schaaff, T.G.; Whetten, R.L. Visible to infrared luminescence from a 28-atom gold cluster. J. Phys. Chem. B 2002, 106, 3410-3415. [CrossRef]

22. Link, S.; El-Sayed, M.A. Spectral properties and relaxation dynamics of surface plasmon electronic oscillations in gold and silver nanodots and nanorods. J. Phys. Chem. B 1999, 103, 8410-8426. [CrossRef]

23. Hartland, G.V. Coherent vibrational motion in metal particles: Determination of the vibrational amplitude and excitation mechanism. J. Chem. Phys. 2002, 116, 8048-8055. [CrossRef]

24. Del Fatti, N.; Bouffanais, R.; Vallée, F.; Flytzanis, C. Nonequilibrium electron interactions in metal films. Phys. Rev. Lett. 1998, 81, 922-925. [CrossRef]

25. Kwak, K.; Thanthirige, V.D.; Pyo, K.; Lee, D.; Ramakrishna, G. Energy gap law for exciton dynamics in gold cluster molecules. J. Phys. Chem. Lett. 2017, 8, 4898-4905. [CrossRef] [PubMed]

26. Zeng, C.; Chen, Y.; Kirschbaum, K.; Appavoo, K.; Sfeir, M.Y.; Jin, R. Structural patterns at all scales in a nonmetallic chiral $\mathrm{Au}_{133}(\mathrm{SR})_{52}$ nanoparticle. Sci. Adv. 2015, 1, e1500045. [CrossRef] [PubMed]

27. Zhao, T.; Herbert, P.J.; Zheng, H.; Knappenberger, K. State-resolved metal nanoparticle dynamics viewed through the combined lenses of ultrafast and magneto-optical spectroscopies. Acc. Chem. Res. 2018, 51, 1433-1442. [CrossRef]

28. Zhou, M.; Zeng, C.; Sfeir, M.Y.; Cotlet, M.; Iida, K.; Nobusada, K.; Jin, R. Evolution of excited-state dynamics in periodic $\mathrm{Au}_{28}, \mathrm{Au}_{36}, \mathrm{Au}_{44}$, and $\mathrm{Au}_{52}$ nanoclusters. J. Phys. Chem. Lett. 2017, 8, 4023-4030. [CrossRef] [PubMed]

29. Zhou, M.; Zeng, C.; Chen, Y.; Zhao, S.; Sfeir, M.Y.; Zhu, M.; Jin, R. Evolution from the plasmon to exciton state in ligand-protected atomically precise gold nanoparticles. Nat. Commun. 2016, 7, 13240. [CrossRef] [PubMed] 
30. Mustalahti, S.; Myllyperkiö, P.; Malola, S.; Lahtinen, T.; Salorinne, K.; Koivisto, J.; Häkkinen, H.; Pettersson, M. Molecule-like photodynamics of $\mathrm{Au}_{102}(\mathrm{pMBA})_{44}$ nanocluster. ACS Nano 2015, 9, 2328-2335. [CrossRef] [PubMed]

31. Stamplecoskie, K.G.; Kamat, P.V. Size-dependent excited state behavior of glutathione-capped gold clusters and their light-harvesting capacity. J. Am. Chem. Soc. 2014, 136, 11093-11099. [CrossRef]

32. Wiseman, M.R.; Marsh, P.A.; Bishop, P.T.; Brisdon, B.J.; Mahon, M.F. Homoleptic Gold Thiolate Catenanes. J. Am. Chem. Soc. 2000, 122, 12598-12599. [CrossRef]

33. Wu, Z.; Suhan, J.; Jin, R. One-pot synthesis of atomically monodisperse, thiol-functionalized $\mathrm{Au}_{25}$ nanoclusters. J. Mater. Chem. 2009, 19, 622-626. [CrossRef]

34. Yam, V.W.-W.; Cheng, E.C.-C.; Zhou, Z.-Y. A highly soluble luminescent decanuclear gold(I) complex with a propeller-shaped structure. Angew. Chem. Int. Ed. 2000, 39, 1683-1685. [CrossRef]

35. Forward, J.M.; Bohmann, D.; Fackler, J.P.; Staples, R.J. Luminescence studies of gold(I) thiolate complexes. Inorg. Chem. 1995, 34, 6330-6336. [CrossRef]

36. Konishi, K.; Iwasaki, M.; Shichibu, Y. Phosphine-ligated gold clusters with core+exo geometries: Unique properties and interactions at the ligand-cluster interface. Acc. Chem. Res. 2018, 51, 3125-3133. [CrossRef] [PubMed]

37. Wing-Wah Yam, V.; Kam-Wing Lo, K. Luminescent polynuclear $\mathrm{d}^{10}$ metal complexes. Chem. Soc. Rev. 1999, 28, 323-334.

38. Lei, Z.; Pei, X.-L.; Guan, Z.-J.; Wang, Q.-M. Full protection of intensely luminescent gold(I)-silver(I) cluster by phosphine ligands and inorganic anions. Angew. Chem. Int. Ed. 2017, 56, 7117-7120. [CrossRef] [PubMed]

39. Wu, Z.; Jin, R. On the ligand's role in the fluorescence of gold nanoclusters. Nano Lett. 2010, 10, $2568-2573$. [CrossRef]

40. Link, S.; El-Sayed, M.A.; Schaaff, T.G.; Whetten, R.L. Transition from nanoparticle to molecular behavior: A femtosecond transient absorption study of a size-selected 28 atom gold cluster. Chem. Phys. Lett. 2002, 356, 240-246. [CrossRef]

41. Kim, H.N.; Lee, M.H.; Kim, H.J.; Kim, J.S.; Yoon, J. A new trend in rhodamine-based chemosensors: Application of spirolactam ring-opening to sensing ions. Chem. Soc. Rev. 2008, 37, 1465-1472. [CrossRef]

42. Sadkowski, P.J.; Fleming, G.R. Photophysics of acid and base forms of rhodamine-B. Chem. Phys. Lett. 1978, 57, 526-529. [CrossRef]

43. Moog, R.S.; Ediger, M.D.; Boxer, S.G.; Fayer, M.D. Viscosity dependence of the rotational reorientation of rhodamine B in mono- and polyalcohols. Picosecond transient grating experiments. J. Phys. Chem. 1982, 86, 4694-4700. [CrossRef]

44. Beaumont, P.C.; Johnson, D.G.; Parsons, B.J. Photophysical properties of laser dyes: Picosecond laser flash photolysis studies of rhodamine 6G, rhodamine B and rhodamine 101. J. Chem. Soc. Faraday Trans. 1993, 89, 4185-4191. [CrossRef]

45. Zhang, X.F.; Zhang, Y.K.; Liu, L.M. Fluorescence lifetimes and quantum yields of ten rhodamine derivatives: Structural effect on emission mechanism in different solvents. J. Lumin. 2014, 145, 448-453. [CrossRef]

46. Kasha, M. Characterization of electronic transitions in complex molecules. Discuss. Faraday Soc. 1950, 9 , 14-19. [CrossRef]

47. Zhou, M.; Lei, Z.; Guo, Q.; Wang, Q.-M.; Xia, A. Solvent dependent excited state behaviors of luminescent gold(I)-silver(I) cluster with hypercoordinated carbon. J. Phys. Chem. C 2015, 119, 14980-14988. [CrossRef]

48. Zeng, C.-j.; Zhou, M.; Gayathri, C.; Gil, R.R.; Sfeir, M.Y.; Jin, R. Au A $_{10}(\mathrm{TBBT})_{10}$ : The beginning and the end of aun(tbbt)m nanoclusters. Chin. J. Chem. Phys. 2018, 31, 555-562. [CrossRef]

49. Devadas, M.S.; Kim, J.; Sinn, E.; Lee, D.; Goodson, T., 3rd; Ramakrishna, G. Unique ultrafast visible luminescence in monolayer-protected $\mathrm{au}_{25}$ clusters. J. Phys. Chem. C 2010, 114, 22417-22423. [CrossRef]

50. Zhou, M.; Tian, S.; Zeng, C.; Sfeir, M.Y.; Wu, Z.; Jin, R. Ultrafast relaxation dynamics of $\mathrm{Au}_{38}\left(\mathrm{SC}_{2} \mathrm{H}_{4} \mathrm{Ph}\right)_{24}$ nanoclusters and effects of structural isomerism. J. Phys. Chem. C 2017, 121, 10686-10693. [CrossRef]

51. Qian, H.; Sfeir, M.Y.; Jin, R. Ultrafast relaxation dynamics of $\left[\mathrm{Au}_{25}(\mathrm{SR})_{18}\right]^{\mathrm{q}}$ nanoclusters: Effects of charge state. J. Phys. Chem. C 2010, 114, 19935-19940. [CrossRef]

52. Varnavski, O.; Ramakrishna, G.; Kim, J.; Lee, D.; Goodson, T., III. Optically excited acoustic vibrations in quantum-sized monolayer-protected gold clusters. ACS Nano 2010, 4, 3406-3412. [CrossRef] [PubMed]

53. Zhou, M.; Jin, R.; Sfeir, M.Y.; Chen, Y.; Song, Y.; Jin, R. Electron localization in rod-shaped triicosahedral gold nanocluster. Proc. Natl. Acad. Sci. USA 2017, 114, E4697-E4705. [CrossRef] [PubMed] 
54. Rafiq, S.; Scholes, G.D. Slow intramolecular vibrational relaxation leads to long-lived excited-state wavepackets. J. Phys. Chem. A 2016, 120, 6792-6799. [CrossRef] [PubMed]

55. Sagar, D.M.; Cooney, R.R.; Sewall, S.L.; Dias, E.A.; Barsan, M.M.; Butler, I.S.; Kambhampati, P. Size dependent, state-resolved studies of exciton-phonon couplings in strongly confined semiconductor quantum dots. Phys. Rev. B 2008, 77, 235321. [CrossRef]

56. Hodak, J.H.; Henglein, A.; Hartland, G.V. Electron-phonon coupling dynamics in very small (between 2 and $8 \mathrm{~nm}$ diameter) Au nanoparticles. J. Chem. Phys. 2000, 112, 5942-5947. [CrossRef]

(C) 2019 by the authors. Licensee MDPI, Basel, Switzerland. This article is an open access article distributed under the terms and conditions of the Creative Commons Attribution (CC BY) license (http://creativecommons.org/licenses/by/4.0/). 